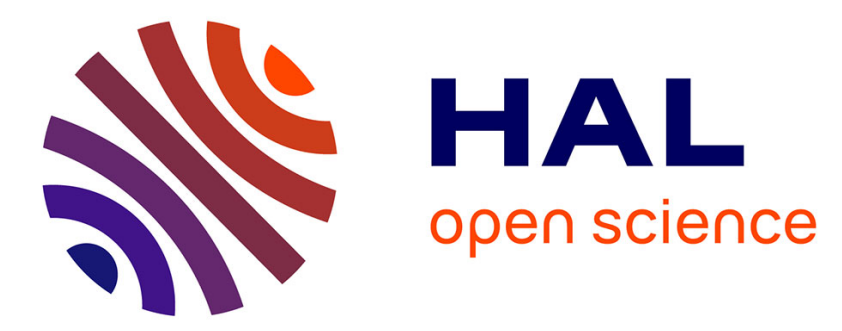

\title{
Erectile response to hypothalamic stimulation in rats: Role of peripheral nerves
}

François Giuliano, Jacques Bernabé, Kathleen Brown, Stéphane Droupy, Gérard Benoît, Olivier Rampin

\section{- To cite this version:}

François Giuliano, Jacques Bernabé, Kathleen Brown, Stéphane Droupy, Gérard Benoît, et al.. Erectile response to hypothalamic stimulation in rats: Role of peripheral nerves. AJP - Regulatory, Integrative and Comparative Physiology, 1997, 273 (6), pp.R1990-R1997. hal-02698407

\section{HAL Id: hal-02698407 https: / hal.inrae.fr/hal-02698407}

Submitted on 1 Jun 2020

HAL is a multi-disciplinary open access archive for the deposit and dissemination of scientific research documents, whether they are published or not. The documents may come from teaching and research institutions in France or abroad, or from public or private research centers.
L'archive ouverte pluridisciplinaire HAL, est destinée au dépôt et à la diffusion de documents scientifiques de niveau recherche, publiés ou non, émanant des établissements d'enseignement et de recherche français ou étrangers, des laboratoires publics ou privés. 
François Giuliano, Jacques Bernabé, Kathleen Brown, Stéphane Droupy, Gérard Benoit and Olivier Rampin

Am J Physiol Regulatory Integrative Comp Physiol 273:1990-1997, 1997.

You might find this additional information useful...

This article cites 23 articles, 2 of which you can access free at:

http://ajpregu.physiology.org/cgi/content/full/273/6/R1990\#BIBL

This article has been cited by 5 other HighWire hosted articles:

Penile erection and micturition events triggered by electrical stimulation of the mesopontine tegmental area

J. C. T. Salas, H. Iwasaki, E. Jodo, M. H. Schmidt, A. Kawauchi, T. Miki, Y. Kayama, M. Otsuki and Y. Koyama

Am J Physiol Regulatory Integrative Comp Physiol, January 1, 2008; 294 (1): R102-R111.

[Abstract] [Full Text] [PDF]

Erectile dysfunction in spontaneously hypertensive rats: pathophysiological mechanisms D. Behr-Roussel, P. Chamiot-Clerc, J. Bernabe, K. Mevel, L. Alexandre, M. E. Safar and F. Giuliano

Am J Physiol Regulatory Integrative Comp Physiol, March 1, 2003; 284 (3): R682-R688. [Abstract] [Full Text] [PDF]

Protein Inhibitor of Nitric Oxide Synthase (NOS) and the N-Methyl-D-Aspartate Receptor Are Expressed in the Rat and Mouse Penile Nerves and Colocalize with Penile Neuronal NOS

T.R. Magee, M.G. Ferrini, H.H. Davila, C.B. Zeller, D. Vernet, J. Sun, R. Lalani, A.L. Burnett, J. Rajfer and N.F. Gonzalez-Cadavid

Biol Reprod, February 1, 2003; 68 (2): 478-488.

[Abstract] [Full Text] [PDF]

Differential ICP responses elicited by electrical stimulation of medial preoptic area

Y. Sato and G. J. Christ

Am J Physiol Heart Circ Physiol, March 1, 2000; 278 (3): H964-H970.

[Abstract] [Full Text] [PDF]

Intracavernous pressure during erection in rats: an integrative approach based on telemetric recording

J. Bernabe, O. Rampin, B. D. Sachs and F. Giuliano

Am J Physiol Regulatory Integrative Comp Physiol, February 1, 1999; 276 (2): R441-R449.

[Abstract] [Full Text] [PDF]

Medline items on this article's topics can be found at http://highwire.stanford.edu/lists/artbytopic.dtl

on the following topics:

Endocrinology .. Hypothalamus

Veterinary Science .. Preoptic Area

Veterinary Science .. Cauda Equina

Physiology .. Iliac Artery

Physiology .. Nerves

Physiology .. Rats

Updated information and services including high-resolution figures, can be found at: http://ajpregu.physiology.org/cgi/content/full/273/6/R1990

Additional material and information about American Journal of Physiology - Regulatory, Integrative and Comparative Physiology can be found at:

http://www.the-aps.org/publications/ajpregu

This information is current as of September 8, 2010 .

The American Journal of Physiology - Regulatory, Integrative and Comparative Physiology publishes original investigations that illuminate normal or abnormal regulation and integration of physiological mechanisms at all levels of biological organization, ranging from molecules to humans, including clinical investigations. It is published 12 times a year (monthly) by the American Physiological Society, 9650 Rockville Pike, Bethesda MD 20814-3991. Copyright () 1997 by the American Physiological Society. ISSN: 0363-6119, ESSN: 1522-1490. Visit our website at http://www.the-aps.org/. 


\title{
Erectile response to hypothalamic stimulation in rats: role of peripheral nerves
}

\author{
FRANÇOIS GIULIANO, ${ }^{1}$ J ACQUES BERNABE, ${ }^{2}$ KATHLEEN BROWN, ${ }^{1}$ \\ STEPHANE DROUPY, ${ }^{1}$ GERARD BENOIT, ${ }^{1}$ AND OLIVIER RAMPIN ${ }^{2}$ \\ 'Service d'Urol ogie et Groupe de Recherche en Urologie, Hôpital de Bicêtre, Faculté de Médecine \\ Paris-Sud, 94270 Le Kreml in Bicêtre Cedex; and 'Laboratoire de Neurobiologie des Fonctions \\ Végétatives, Institut National de la Recherche Agronomique, 78352 J ouy-en-J osas Cedex, France
}

\begin{abstract}
Giuliano, François, J acques Bernabé, Kathleen Brown, Stéphane Droupy, Gérard Benoit, and Olivier Rampin. Erectile response to hypothalamic stimulation in rats: role of peripheral nerves. Am. J . Physiol. 273 (Regulatory Integrative Comp. Physiol. 42): R1990-R1997, 1997.The role of peripheral parasympathetic and sympathetic pathways was explored in erectile responses elicited by hypothalamic medial preoptic area (MPOA) stimulation in adult maleanesthetized rats. Under control conditions, M POA stimulation reliably elicited erectile responses evidenced by an increase of the intracavernous pressure-to-blood pressure ratio. The erectile response was abolished by 1 ) acute bilateral section of cavernous or pelvic nerves or cauda equina and 2) chronic lesions of pelvic nerves or cauda equina. Acute section of the hypogastric nerve did not significantly decrease the erectile response. The erectile response was significantly depressed after acute or chronic sections of the paravertebral sympathetic chain at the L4-L5 level or chemical sympathectomy with 6-hydroxydopamine. The decrease due to acute sympathetic chain lesion was reversed by bilateral ligation of the external iliac arteries. Accordingly MPOA stimulation elicits erectile responses via 1 ) activation of the parasympathetic outflow conveyed by the pelvic and cavernous nerves and 2) activation of neural fibers conveyed by the sympathetic pathways. We propose that sympathetic fibers running in the paravertebral sympathetic chain are responsible for vasoconstriction of nonpenile areas to divert blood to the penis, allowing the dramatic increase of penile arterial inflow required for erection.
\end{abstract}

medial preoptic area; penis; paravertebral sympathetic chain; hypogastric nerve; pelvic arteries

LOCAL MECHANISMS OF PENILE erection are penile arteries dilation and relaxation of the smooth muscle fibers of the corpus cavernosum and corpus spongiosum (1). The penile arterial supply and erectile tissue receive innervation from both sympathetic and parasympathetic components of the autonomic nervous system. Penile parasympathetic innervation, originating in the sacral spinal cord, is conveyed by the pelvic and cavernous nerves. It is widely recognized as the proerectile pathway. Sympathetic innervation to the pelvis, originating in the thoracol umbar spinal cord, is conveyed by both the prevertebral outflow, including the hypogastric and cavernous nerves, and the paravertebral outflow, including the paravertebral sympathetic chain and the pudendal or pelvic and cavernous nerves (10). The antierectile role of fibers running in the paravertebral sympathetic chain has been demonstrated in anesthetized animals $(11,14,15,25,26)$. Conversely hypogastric nerve stimulation elicited penile protrusion in anesthetized animals, providing evidence of a proerectile role for this nerve $(2,5,26)$.

Therefore the roles for spinal autonomic nuclei controlling penile erection are complex. These nuclei are recruited by information from peripheral and/or central origin $(10,22)$. The medial preoptic area of the hypothalamus (MPOA) represents a key structure in the supraspinal control of penile erection (22). Recent experiments show that MPOA stimulation in the anesthetized rat elicits a complex urogenital response, including penile erection, and intracavernous pressure increase $(12,19)$. However the peripheral neural pathways activated by MPOA stimulation and involved in the erectile response remain unknown. The first aim of the present study was to explore the relationships between MPOA and peripheral neural pathways involved in the control of local mechanisms of penile erection.

Antierectile sympathetic fibers exert their role via an increase in the tone of penile smooth muscle fibers surrounding the sinusoidal spaces, as sympatholytic agents, i.e., $\alpha$-adrenoceptor antagonists, elicit penile erection when delivered intracavernously (1). Histochemical evidence for the adrenergic innervation of penile vessels (i.e., deep penile arteries, helicine arteries) has been provided $(7,21)$, and norepinephrine contracts these vessels (1). Therefore the sympathetic nervous system also exerts its antierectile role very likely via vasoconstriction of penile arteries. On the other hand, it is noteworthy that a 10 - to 30-fold increase of pudendal artery blood flow to the penis occurs in anesthetized dogs and monkeys during the early stage of penile erection (i.e., during the latent and tumescence phases) elicited by pelvic nerve stimulation $(6,17)$. This dramatic vasodilation of the arterial supply to the penis very likely requires a redistribution of blood in the pelvis. The second aim of this study was to explore the role of the sympathetic innervation in the necessary pelvic blood rearrangements occurring during penile erection elicited by MPOA stimulation; in other terms, addressing whether the sympathetic innervation to nonpenile regions vasoconstrict the pelvis vascularization, thereby shunting blood to the erectile tissue.

\section{MATE RIAL AND METHODS}

Adult male Sprague-Dawley rats (Iffa-Credo, L'Arbresle, France), weighing 450-500 g, were anesthetized by intraperitoneal injection of pentobarbital sodium $(60 \mathrm{mg} / \mathrm{kg}$, Sanofi, Libourne, France). During the experiment, the animals were placed on a homeothermic blanket and received additional 
intraperitoneal injections of $0.1 \mathrm{ml}$ of pentobarbital sodium on signs of awakening. The trachea was cannulated to prevent aspiration of saliva and to apply artificial ventilation when required. A catheter was inserted into the left carotid artery for blood pressure (BP) monitoring. The penis was denuded of skin to insert the tip of a catheter fitted with a 25-gauge needle into one corpus cavernosum for intracavernous pressure (ICP) monitoring. A catheter was placed in the jugular vein for drug injection. Arterial and cavernosal catheters filled with heparinized saline $(100 \mathrm{U} / \mathrm{ml})$ were connected to pressure transducers (E M 750, Elcomatic, Glasgow, UK). The pressure signals were amplified (Bionic Instruments, N ozay, France) and digitized via an analog-to-digital converter (Labmaster DMA, Scientific Solutions, Solon, $\mathrm{OH}$ ). They were recorded at a sampling rate of fivevalues per second, converted to millimeters mercury after calibration (Unkelscope, MIT, Lexington, MA), and stored in a computer (AFC, Paris, France).

Electrode implants in the MPOA were performed unilaterally in the right hemisphere using concentric bipolar stainless steel el ectrodes built in the laboratory. Stereotaxic coordinates were achieved with the head inclined $3 \mathrm{~mm}$ below the interaural line. The coordinates were $0.20-0.25 \mathrm{~mm}$ posterior to bregma, $0.4 \mathrm{~mm}$ lateral to the midline, and $8.4 \mathrm{~mm}$ below the skull surface. Stimulation of the MPOA consisted of square-wave pulses delivered for $1 \mathrm{~min}$. Stimulation parameters were frequency $30 \mathrm{~Hz}$, pulse duration $2 \mathrm{~ms}$, and intensity $7 \mathrm{~V}$. Recording of ICP and arterial BP started $1 \mathrm{~min}$ before the onset of MPOA stimulation and lasted $3 \mathrm{~min}$. Two consecutive stimulations were separated by a 5-min resting period.

In preliminary experiments, the influence of additional injections of intraperitoneal pentobarbital sodium on ICP increase elicited by MPOA stimulation was examined. When electrical stimulation was applied 10, 20, 30, and 40 min after injection of $0.1 \mathrm{ml}$ ip pentobarbital sodium, we did not record any significant change in the erectile response. Consequently, when an additional injection of pentobarbital sodium was performed, stimulation was delayed for $10 \mathrm{~min}$.

The stimulation schedule included a control condition of two trials with each polarity and, according to the experiments, two trials with each polarity after nerve lesion and/or arterial ligation or muscle relaxation. At the end of the experiments, electrocoagulation was performed at the site of the el ectrode implant by passing a current of $20 \mathrm{~mA}$ for $20 \mathrm{~s}$ in each polarity through the electrode. Rats were then deeply anesthetized and transcardially perfused with a $10 \%$ F ormalin solution. Their brains were removed and cut serially in the frontal plane on a cryostat into $24-\mu \mathrm{m}$-thick sections. One in three brain slices was mounted on gelatinized slides and examined under a light microscope for confirmation of electrode placement. Only those animals with electrodes located in the posterior part of MPOA were considered in the results, and rats in which electrode displacement was observed during the experiments were discarded from the study.

\section{Acute Experiments}

In six rats, section of the cavernous nerve, homolateral then contralateral to the stimulated MPOA, was performed. Sections were performed $3 \mathrm{~mm}$ distally to the major pelvic ganglion (Fig. 1). In six rats, the contralateral then homolateral cavernous nerves were acutely severed. In this case, four trials were performed after unilateral section of the cavernous nerve. The first two trials were used for comparison with control conditions, and the last two trials were compared with the response after bilateral section. In eight rats, the hypogastric nerves were bilaterally severed $3 \mathrm{~mm}$ proximal to the major pelvic ganglion (Fig. 1). In six rats, the pelvic nerves were bilaterally sectioned $3 \mathrm{~mm}$ proximal to the major pelvic

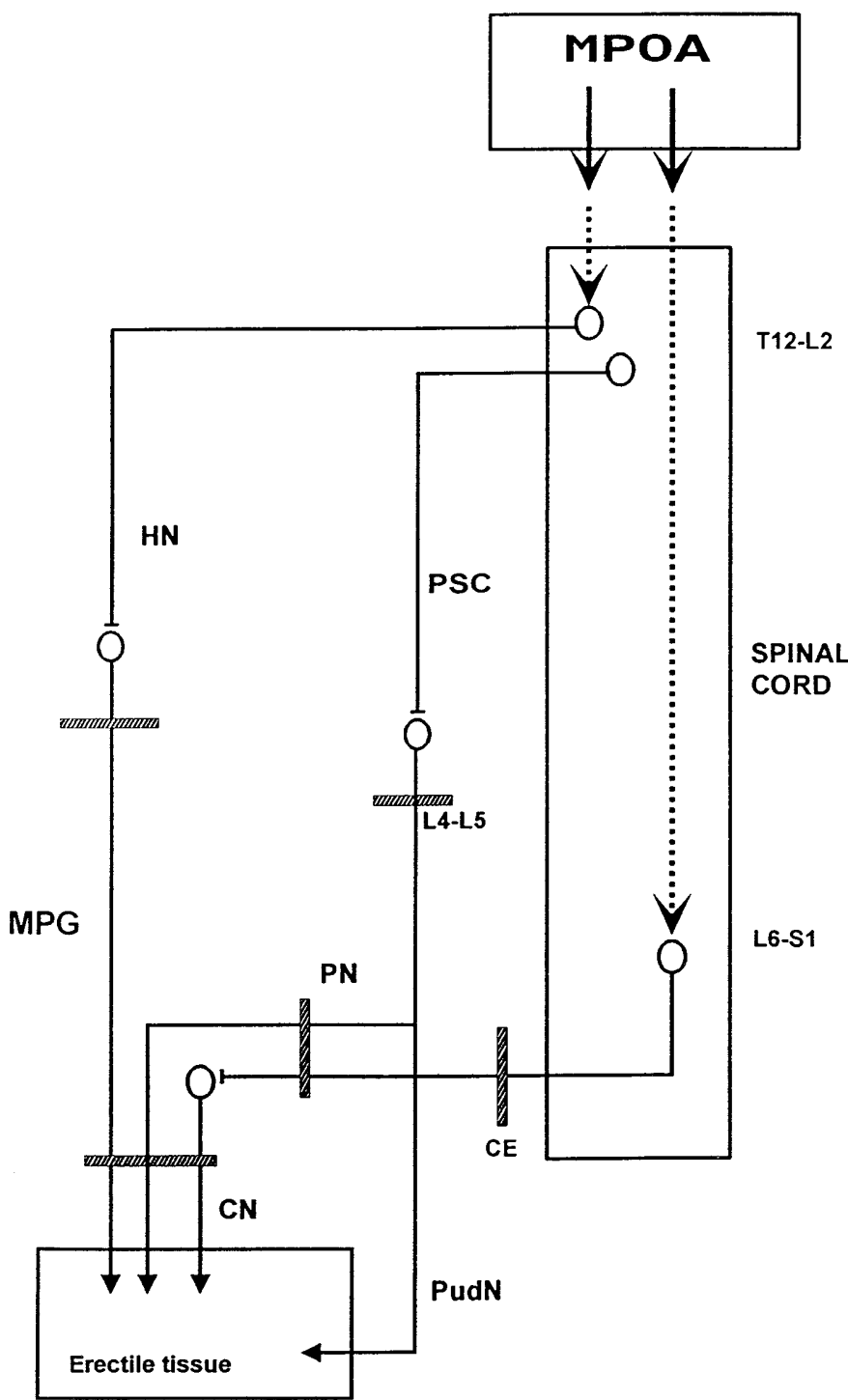

Fig. 1. Diagrammatic representation of peripheral autonomic pathways potentially involved in erectile response elicited by medial preoptic area (MPOA) stimulation. Sites of neural lesions are represented by hatched bars. No direct projections from MPOA to spinal autonomic nuclei have been reported. CE, cauda equina; CN, cavernous nerve; HN, hypogastric nerve; L4-L5, 4th and 5th lumbar levels of the paravertebral sympathetic chain; L6-S1, 6th lumbar and 1st sacral level of the spinal cord; MPG, major pelvic ganglion; PN, pelvic nerve; PSC, paravertebral sympathetic chain; PudN, pudendal nerve; T12-L2, 12th thoracic to 2nd lumbar level of the spinal cord.

ganglion (Fig. 1). In six rats, the cauda equina was sectioned after removing the spinal process of L5 (Fig. 1). In seven rats, the paravertebral sympathetic chain was cut at the level of L4-L5 (Fig. 1). In 11 rats, ligatures were placed bilaterally around the external iliac artery proximal to its parietal branches (Fig. 2) before the first two stimulations, then the paravertebral sympathetic chain was sectioned at the level of L4-L5, followed by two stimulations. Finally, the previously placed arterial ligatures were tightened and MPOA was again stimulated twice.

\section{Chronic Experiments}

In the following groups, stimulation of the MPOA was performed 6 days after the surgical procedure. In six rats, 


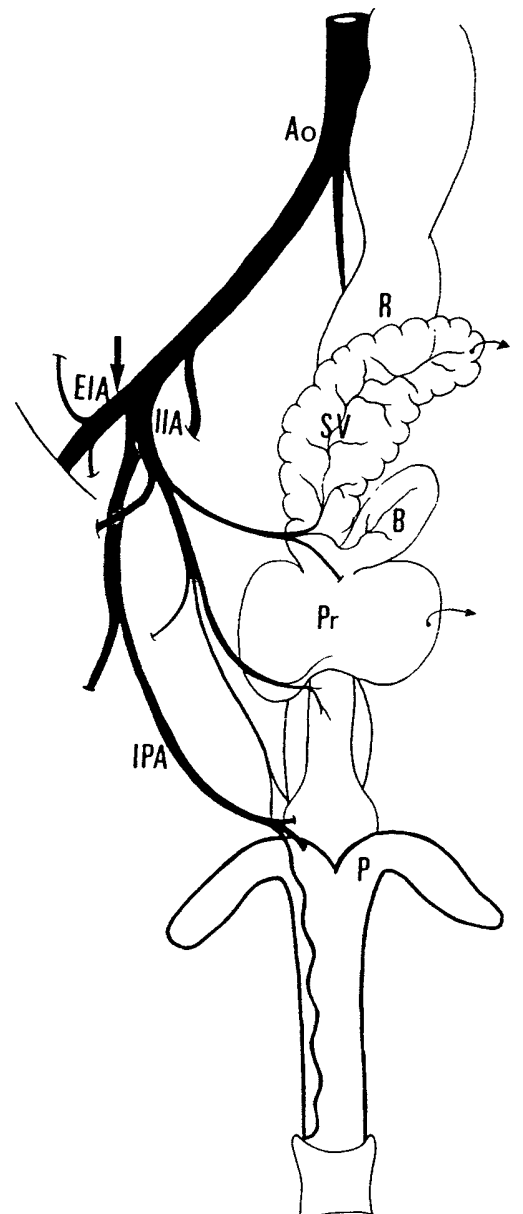

Fig. 2. Ventral view of anatomic arrangement of pelvic arterial supply in male rats. Site of artery ligation is represented by arrows. Ao, aortic bifurcation; B, bladder; EIA, external iliac artery; IIA, internal iliac artery; IPA, internal pudendal artery; $\mathrm{P}$, penis; $\mathrm{Pr}$, prostate; $\mathrm{R}$, rectum; $\mathrm{SV}$, seminal vesicles.

bilateral section of the pelvic nerves was performed, and rats received bladder massages twice daily until the experiment. In six rats, the pelvic nerves were only freed from the surrounding tissues. In two rats, the cauda equina was sectioned after removing the spinal process of L5, and these rats also received bladder massages. In five rats, a suprapubic midline incision and temporary removal of the gut from the abdominal cavity were performed. In seven rats, bilateral section of the sympathetic chain at the level of L4-L5 was performed through a suprapubic midline incision after shifting the aorta and vena cava laterally. Surgical wounds were sutured in separate layers.

\section{Pharmacological Treatments}

Seven rats underwent chemical sympathectomy with a single injection of 6-hydroxydopamine (6-OHDA, $100 \mathrm{mg} / \mathrm{kg}$ ) into the dorsal vein of the penis performed $48 \mathrm{~h}$ before MPOA stimulation. Seven rats, acting as controls, received an injection of the same volume of saline containing ascorbic acid via the same route. In six rats, M POA was stimulated before and after muscle relaxation (gallamine triethiodide, $30 \mathrm{mg} / \mathrm{kg}$ iv) and these rats were artificially ventilated.

\section{Drugs}

6-OHDA was purchased from Sigma, Saint-Quentin Fallavier, France, and was dissolved at the required concentration in $0.9 \%$ saline containing $10 \mathrm{mg}$ ascorbic acid/l. Gallamine triethiodide (Flaxedil) was purchased from Specia, Paris, France.

\section{Data Analysis}

A description of ICP changes elicited by neural stimulation in anesthetized rats has been previously reported (9). In the present study, we averaged ICP during the minute before stimulation and termed this value flaccid ICP (9). We also measured the most characteristic parameter of the erectile response to electrical stimulation, i.e., the ICP-to-BP ratio (ICP/BP) during the full-tumescence phase (11). Variations caused by neural lesions were assessed by comparison of ICP/BP before and after the lesion in the samerats. Additionally, consequences of acute section of the sympathetic chain were searched for on flaccid ICP values. After chronic neural sections and chemical sympathectomy, results from the operated rats were averaged for each experimental group and compared with the corresponding control group. ICP/BP was averaged for each rat for the two trials performed under the same conditions, then averaged for the group. Results are presented as the mean of the mean \pm SE for each group. Student's t-test was used to compare the changes in flaccid ICP and erectile response to MPOA stimulation before and after nerve section or drug injection. Variations of flaccid ICP and ICP/BP were considered significant for $\mathrm{P}<0.05$. Analysis of variance (ANOVA) was used to compare 1 ) changes in flaccid ICP and ICP/BP in rats submitted to sympathetic chain section and artery ligation (1-way ANOVA with repeated measures) and 2) changes in erectile response in rats that underwent a chronic lesion of the sympathetic chain with responses of a control group and a group of shamoperated rats (1-way ANOVA). Student-Newman-Keuls test was performed on significant differences, with a limit of significance of $\mathrm{P}<0.05$.

\section{RESULTS}

Under control conditions, stimulation of the posterior region of the MPOA consistently elicited an ICP increase that persisted until stimulation stopped.

\section{Acute Experiments}

Effects of acutesection of neural pathways. Sectioning of the cavernous nerve homolateral to the stimulated MPOA was responsible for a significant decrease of ICP/BP (0.59 \pm 0.06 before and $0.37 \pm 0.06$ after section, $P<0.001, n=6$, Fig. 3). Additional section of the contralateral cavernous nerve abolished the ICP response to MPOA stimulation, as ICP/BP during the stimulation period did not differ from that measured during the minute before MPOA stimulation, i.e., the flaccid period. When the cavernous nerve contralateral to the MPOA stimulation site was sectioned first, ICP/BP was significantly lowered $(0.57 \pm 0.03$ before vs. $0.29 \pm 0.06$ after section, $P<0.01, n=6$, Fig. 3 ). Additional section of the homolateral cavernous nerve abolished the ICP increase elicited by MPOA stimulation. Student's t-test yiel ded no statistical difference for ICP/BP in rats in which the homolateral cavernous nerve was sectioned first or the contralateral cavernous nerve was sectioned first ( $P=0.43$ ).

Bilateral section of the pelvic nerves abolished the erectile response elicited by MPOA $(n=6)$. The ICP 

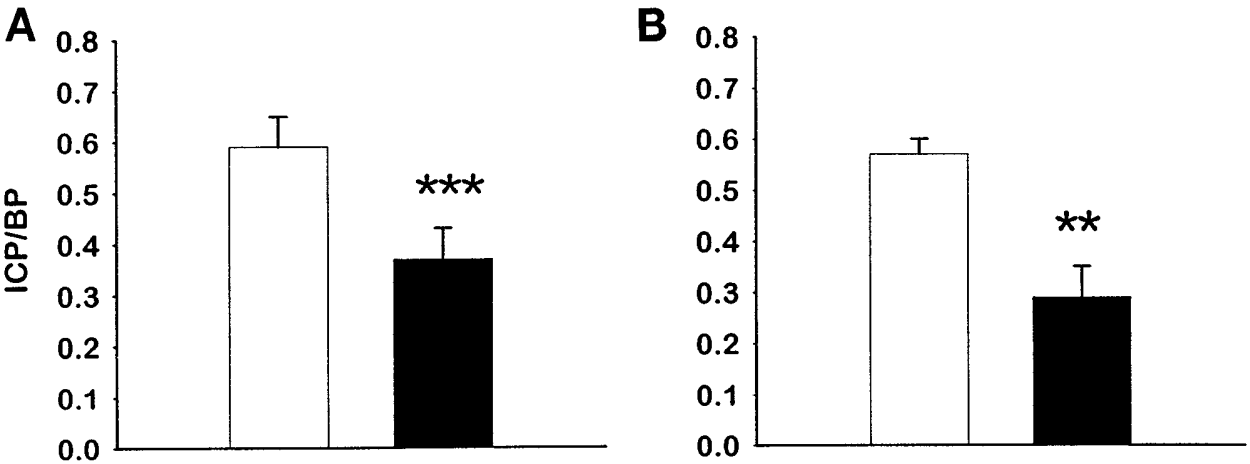

Fig. 3. Comparison of the intracavernous pressure-to-blood pressure ratio (ICP/BP) characterizing erectile response elicited by MPOA stimulation before (open bars) and after (filled bars) acute section of various sets of peripheral nerves. A: cavernous nerve (CN) homolaterally to the stimulation site $(\mathrm{n}=6)$; *** $\mathrm{P}<0.001$. B: CN contralaterally to the stimulation site $(n=6)$; $* * P<0.01$. C: hypogastric nerves (HN, $\mathrm{n}=8$ ); no statistical difference (ns). D: lumbar sympathetic chain at the L4-L5 level $(\mathrm{n}=7)$; $* \mathrm{P}<0.05$. $\mathrm{E}$ : lumbar sympathetic chain at the L4-L5 level and after further bilateral ligation of the external iliac and obturator arteries (hatched bar, $\mathrm{n}=11$ ); $* \mathrm{P}<0.05$.

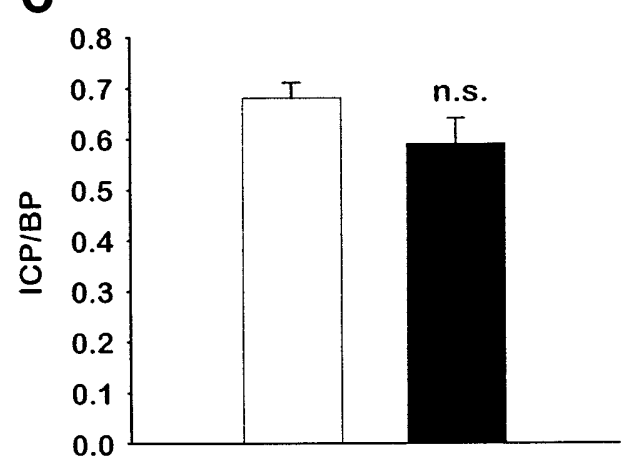

D
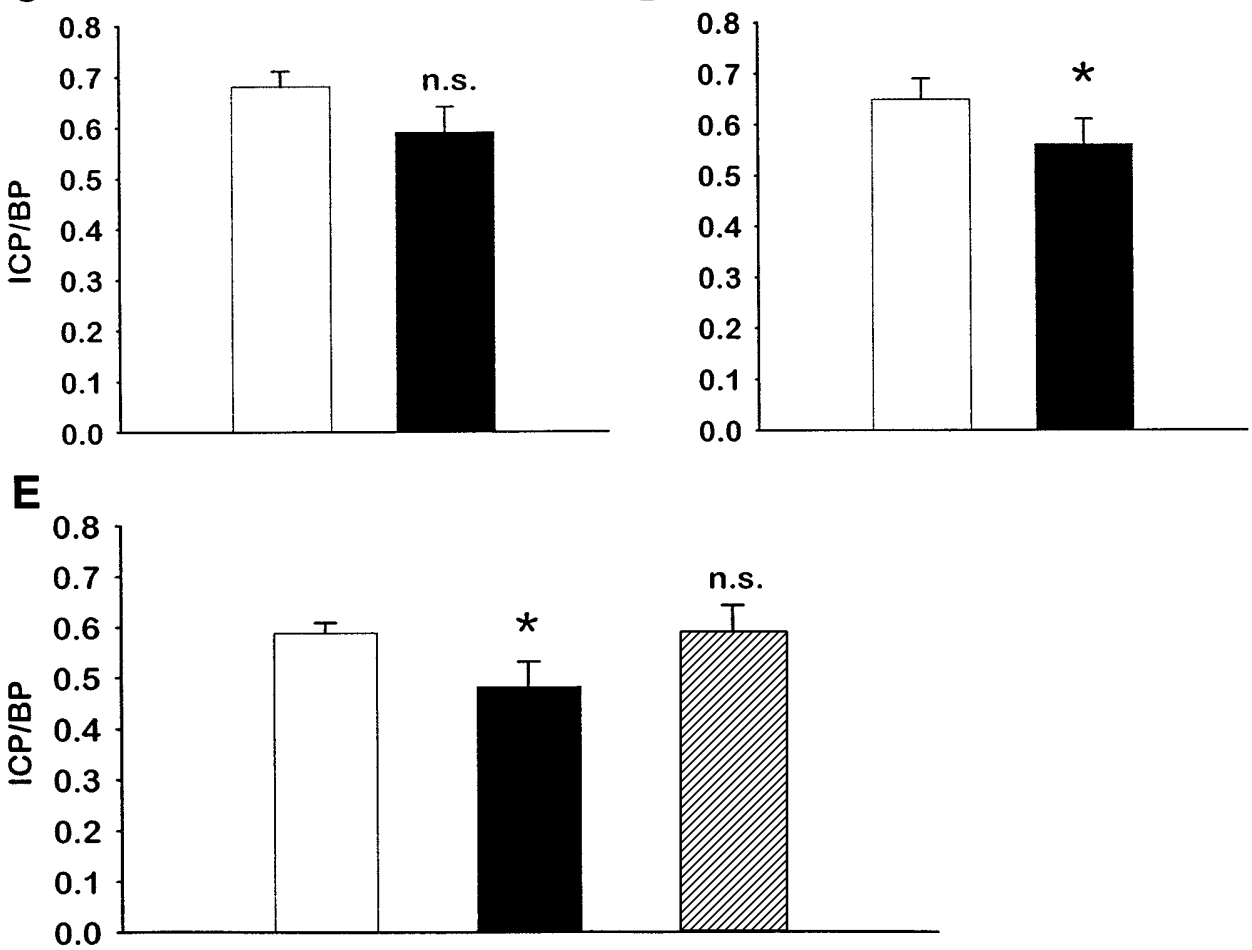

increase elicited by MPOA stimulation was also abolished after acute section of the cauda equina $(n=6)$. Bilateral section of the hypogastric nerves decreased ICP/BP from $0.68 \pm 0.03$ to $0.59 \pm 0.05$, although there was not a statistically significant difference $(P=0.17$, $\mathrm{n}=8$, Fig. 3). After section of the paravertebral sympathetic chain at the level of L4-L5, the ICP/BP increase elicited by MPOA stimulation was decreased to $0.56 \pm 0.05$ vs. $0.65 \pm 0.04$ before $(P<0.05, n=7$, Fig. 3).

Effects of sympathetic chain lesion combined with arteries ligation. In another 11 rats, the decrease in erectile response to MPOA stimulation after paravertebral sympathetic chain section at the L4-L5 level was confirmed. ANOVA revealed a statistical difference in ICP/BP during MPOA stimulation under control conditions, after section of the sympathetic chain, and after bilateral ligation of the proximal external iliac arteries $[F(2,30)=3.98, P<0.05]$. ICP/BP, significantly reduced by sympathetic chain section $(P<0.05)$, was restored to control levels by artery ligation (Fig. 3).
Flaccid ICP was $9.24 \pm 0.87 \mathrm{mmHg}$ in control conditions, $8.88 \pm 0.91 \mathrm{mmHg}$ after sectioning the sympathetic chain, and $7.24 \pm 1.74 \mathrm{mmHg}$ after arterial ligation. One-way ANOVA with repeated measures on ranks did not evidence any statistically significant difference $\left(\chi^{2}=0.73, P=0.70\right)$.

\section{Chronic Experiments}

Effects of chronic section of neural pathways. No ICP increase occurred in response to MPOA stimulation in any of the rats 6 days after bilateral section of the pelvic nerves $(n=6)$ or cauda equina lesion $(n=2)$. After section of the sympathetic chain at the L4-L 5 level, the ICP/BP decreased to $0.10 \pm 0.05$ ( $n=7$, no erectile response was recorded in 5 rats) vs. $0.70 \pm 0.03$ in control rats and $0.62 \pm 0.09$ in sham-operated rats. A significant difference in ICP/BP was observed between the groups $[F(2,16)=41.2, P<0.0001]$. StudentNewman-Keuls test revealed that rats whose sympathetic chain was sectioned displayed a significantly 

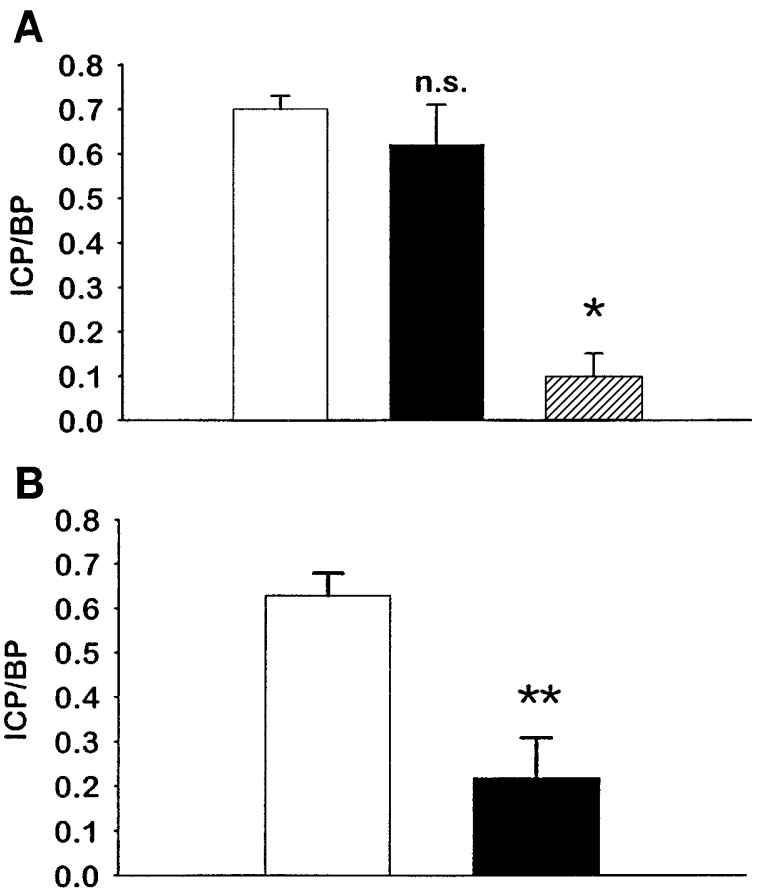

Fig. 4. Comparison of ICP/BP, characterizing erectile response elicited by MPOA stimulation in rats with or without chronic lesions of sympathetic pathways. A: control rats (open bar, $n=7$ ) are compared with sham-operated rats (filled bar, $\mathrm{n}=5$ ) and rats that underwent a section of the lumbar sympathetic chain 6 days before (hatched bar, $\mathrm{n}=7,2$ responders, 5 nonresponders) at the L4-L5 level. $* \mathrm{P}<0.05$ $B$ : comparison of erectile response in control rats (open bar, $n=7$ ) and rats treated with intravenous 6-hydroxydopamine $48 \mathrm{~h}$ before (filled bar, $\mathrm{n}=7,2$ responders, 5 nonresponders). $* * \mathrm{P}<0.01$.

lower ICP/BP than control and sham-operated rats $(P<0.05$, Fig. 4).

Effects of chemical sympathectomy. 6-OHDA treatment significantly decreased ICP/BP $(0.22 \pm 0.09$ in 6-OHDA-treated rats, $n=7$, no erectile response was recorded in 5 rats, vs. $0.63 \pm 0.05$ in the control group, $\mathrm{P}<0.01$, Fig. 4).

Effects of muscle relaxation. Muscle relaxation was not responsible for any significant change in ICP/BP $(0.58 \pm 0.05$ before and $0.66 \pm 0.08$ after injection, $\mathrm{P}=$ 0.26 ) elicited by MPOA stimulation (Fig. 5).

\section{DISCUSSION}

The present study demonstrates that the erectile response el icited by MPOA stimulation is dueto recruit-

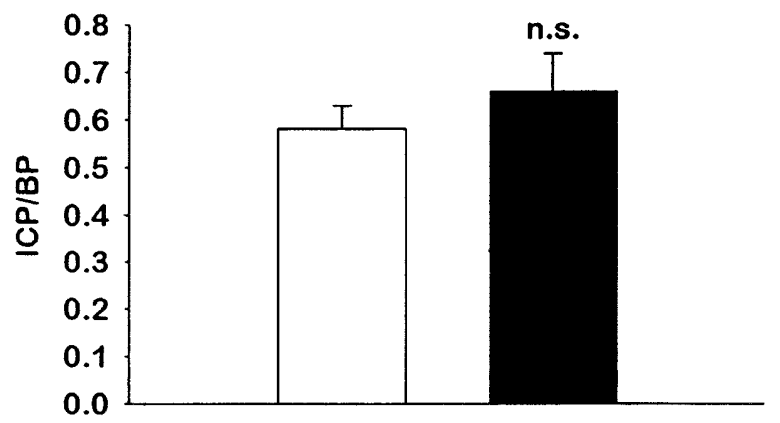

Fig. 5. Comparison of erectile response el icited by MPOA stimulation before (open bar) and after (filled bar) muscle relaxation with gallamine triethiodide (30 mg/kg iv, $\mathrm{n}=6$ ). ment of autonomic outflows derived from the spinal cord and, accordingly, that MPOA is involved in the control of autonomic nuclei that regulate penile erection at the spinal level.

\section{Parasympathetic Outflow}

In the rat, the parasympathetic outflow, including those fibers destined to the penis, arises from the L6-S1 spinal cord, runs in the corresponding ventral spinal roots and pelvic nerve (23), joins the major pelvic ganglion, and is conveyed more distally by the cavernous nerve. Stimulation of the pelvic and cavernous nerves elicits penile erection in various animal species including humans, whereas lesions of these nerves are responsible for impotence $(10,16,18)$. It is therefore widely accepted that penile erection involves activation of the sacral parasympathetic outflow in response to activation of supraspinal structures and/or peripheral afferents. Physiological evidence that the proerectile lumbosacral parasympathetic outflow is reflexively activated by stimulation of dorsal penile nerve afferents has been provided in the rat (24). Nevertheless, to our knowledge, there is no clear evidence that the parasympathetic outflow is recruited during penile erection elicited by stimulation integrated at supraspinal levels. In the present experiment, a lesion of the cauda equina comprising the L6 and S1 spinal nerves or bilateral lesions of the pelvic or cavernous nerves abolishes the ICP increase elicited by MPOA stimulation. Accordingly, we provide the first evidence that activation of parasympathetic fibers derived from the L6-S1 spinal cord and subsequently traveling in the pelvic and cavernous nerves is an essential condition for erection to occur in response to MPOA stimulation. Although we have pointed out the role of the sacral parasympathetic pathways, we cannot exclude that other sources of neural fibers may be involved in theerectileresponseto MPOA stimulation.

It is noteworthy that no direct projection from MPOA to the spinal cord has been reported in rats (27). MPOA sends projections to the paraventricular nucleus, a hypothalamic nucleus whose stimulation elicits penile erection in conscious rats (3). MPOA densely innervates the midbrain periaqueductal gray matter, a structure that plays a role in cardiovascular, neuroendocrine, and reproductive functions, and sends projections to the raphe nuclei, which contain serotoninergic neurons (27). Further experiments are needed to explore which supraspinal and spinal pathways are recruited by electrical stimulation of MPOA and are responsible for activation of the parasympathetic outflow. Comparison of the decreases of erectile response after homolateral and contralateral cavernous nerve sections suggests that the pathways derived from the MPOA mainly exert their action via a homolateral projection to the spinal cord. However, there is also a significant contralateral projection from MPOA to proerectile spinal nuclei, suggesting a possible compensatory role in case of hemisection of the spinal cord. 


\section{Sympathetic Outflow}

In the rat, sympathetic preganglionic neurons to the pelvic organs are present in the T13-L2 spinal segments, project to the inferior mesenteric ganglion, and travel distally in the hypogastric nerves. Postganglionic fibers cross the pelvic plexus, and some of them join the pelvic organs through the cavernous nerves. Other sympathetic fibers travel caudally in the paravertebral sympathetic chain and reach the pelvic organs via the pelvic and pudendal nerves (13). Accordingly both prevertebral and paravertebral sympathetic outflows convey fibers to the pelvis.

\section{Hypogastric Nerves}

In rats, electrical stimulation of the hypogastric nerve does not elicit any ICP increase $(8,11)$. Conversely, evidence for a proerectile role for the hypogastric nerve has been provided in rabbits, cats, and dogs $(2,5,26)$. In these species, stimulation of the hypogastric nerve elicited an increase of penile volume, as measured with plethysmography $(2,26)$. In contrast, in other reports in rabbits, cats, and dogs, stimulation of the same nerve elicited retraction and pallor of the penis, decreased blood flow, or subsidence of erection elicited by stimulation of the sacral anterior roots or the cavernous nerve $(14,15,25)$. Accordingly, in these species presence of proerectile fibers in the hypogastric nerve still remains a matter of debate, and pro- and antierectile effects may rely on different stimulation parameters recruiting preferentially one or the other fiber populations in different proportions. The penile response only reflects the sum of pro- and antierectile effects of the stimulated fibers and does not demonstratetheir presence or the relative percentage of them. If pro- and antierectile fibers were activated in equipotent number by stimulating the hypogastric nerve, then no responsewould be observed. Accordingly, MPOA stimulation represents a more integrative approach to explore the role of the hypogastric nerve in penile erection rather than stimulating the nerve itself. In our experiment, erectile response to MPOA stimulation was decreased after hypogastric nerve section; nevertheless, this decrease was nonsignificant. The decrease of erectile response may result from interruption of a proerectile outflow conveyed by this nerve. In the rat, the hypogastric nerve has been al so suggested to play a proerectile role after interruption of the sacral proerectile outflow (8). From our experiment, we are not able to confirm this hypothesis in the present rat model, as no penile response occurred after section of either the pelvic nerves or cauda equina.

\section{Lumbosacral Paravertebral Sympathetic Chain}

There is consistent experimental evidence demonstrating an antierectile role of the sympathetic nervous system $(6,11,14,15,25,26)$. These data have been collected in anesthetized animals from experiments using electrical stimulation or lesions of peripheral sympathetic pathways. In accordance with these data, electrical stimulation of the cavernous nerve elicited better intracavernous pressure increases in rats after chemical sympathectomy with 6-OHDA compared with control rats (9). Furthermore, the presence of a permanent antierectile sympathetic tone exerted on smooth muscle fibers of the corpus cavernosum has been suggested by pharmacological experiments (1) and occurrence of an increase in penile volume in rabbits after section of the sympathetic chain $(4,26)$.

In contrast to previous experiments (9) chemical sympathectomy with 6-OHDA led to a dramatic decrease of erection elicited by MPOA stimulation. It is noteworthy that erectile response to MPOA stimulation implies recruitment of spinal nuclei controlling local mechanisms of penile erection. Conversely, cavernous nerve stimulation only recruits very distal, mainly postganglionic, autonomic pathways. We propose that the decrease of the erectile response to MPOA stimulation after chemical sympathectomy is due to a lesion of proerectile sympathetic fibers. These fibers would not be recruited by cavernous nerve stimulation. As acute and chronic paravertebral sympathetic chain sections decreased the erectile response to MPOA stimulation, we hypothesize the presence of these proerectile sympathetic fibers in the paravertebral sympathetic chain. The physiological evidence for these proerectile fibers remains to be provided.

Penile engorgement with blood is a rapid event occurring at the beginning of erection and is supported by a dramatic increase of the arterial blood flow to the penis due to relaxation of smooth muscle fibers of the wall of penile arteries (1). Regulation of resistance and flow in the vasculature is classically controlled by the sympathetic nervous system. Because penile erection requires blood diversion to the penis, we propose that activation of a contingent of sympathetic fibers is responsible for an increased vascular tone in pelvic arteries except those supplying the penis, thus all owing an increased flow in the penile arterial supply. These fibers may be conveyed by the lumbar sympathetic chain and may be recruited by MPOA stimulation, by that mean exerting a proerectile role. This hypothesis is supported by the previous report of erectile dysfunction in rabbits and guinea pigs after lumbosacral sympathetic lesions (4). Further arguments for such an hypothesis are provided by the arterial ligation experiments. Ligation of the proximal external iliac artery restored the erectile response to MPOA stimulation previously decreased by the lumbar sympathetic chain lesion. In rats, the common iliac arteries arising from the aortic bifurcation give rise to the external and internal iliac arteries. The external iliac arteries represent the main arterial blood supply to the hindlimbs. The penile arterial supply arises from the internal pudendal arteries and branches of the internal iliac arteries and terminates as the bulbospongiosal, cavernosal, and dorsal arteries. Accordingly, bilateral ligation of the proximal external iliac arteries increases the amount of blood available for the remaining branches of the iliac arterial system, including the internal pudendal arteries. Thus we provide experimental arguments for a role of sympathetic fibers conveyed by the 
lumbosacral sympathetic chain in the erectile response to MPOA stimulation.

In rabbits, penile protrusion was observed after ligation of the external iliac arteries and acute sympathetic chain lesion (26). This increase in penile volume could involve corpora cavernosa and/or spongiosum. This observation was made on a flaccid penis. In the rat, we did not observe any variation in flaccid ICP before or after acute section of the sympathetic chain combined with ligation of the external iliac arteries. Differences may be due to 1) an important role for corpus spongiosum in the penile protrusion observed in rabbits after interruption of vasoconstrictor pathways and 2) the fact that an increase in volume may occur without an increase in pressure. Ther efore our results do not draw similar conclusions on the flaccid penis of the rat. On the other hand, in rabbits an alteration of the penile response to either hypogastric or pelvic nerve stimulation with low frequencies after chronic section of the sympathetic chain was reported (26). In our experiment, comparable conclusions can be drawn on the role of the sympathetic outflow conveyed by the sympathetic chain, as section of this neural pathway altered penile erection elicited by MPOA stimulation.

\section{Somatic Outflow}

It has been shown in rats that, in the context of copulation and erections taking their origin in supraspinal structures, penile responses involved activation of both autonomic and somatic outflows (22). In anesthetized rats, stimulation of the cavernous nerve leads to infrasystolic increases of intracavernous pressure, i.e., an ICP/BP $<1$. In contrast, additional stimulation of the motor pudendal nerve increases intracavernous pressure to suprasystolic values (11). In the present experiment, el ectrical stimulation of the MPOA al ways elicits penile pressure increases less than systolic levels, as evidenced by an ICP/BP al ways $<1$. We conclude that it represents the expression of autonomic pathways activation only, suggesting that no activation of perineal striated muscles occurred under these experimental conditions. This is confirmed by the lack of effect of muscle relaxation on the erectile response to MPOA stimulation.

In conclusion, the present results demonstrate that in theanesthetized rat MPOA stimulation elicits penile erection through recruitment of proerectile fibers conveyed by the parasympathetic lumbosacral outflow and recruitment of fibers running in the lumbosacral paravertebral sympathetic chain and perhaps in the hypogastric nerve. These sympathetic fibers could beresponsible for a diversion of blood from other regions to the penis by exerting a vasoconstriction to nonpenile regions in the pelvis, thereby shunting blood to the erectile tissue. Under the present experimental conditions, no evidence can be provided for the concomitant inhibition of the activity of paravertebral sympathetic vasoconstrictor neurons supplying the erectile tissue occurring during penile erection and previously evidenced under other experimental conditions (9). MPOA stimulation demonstrated the coordination of both sympathetic and parasympathetic spinal nuclei involved in the local control of penile erection. MPOA stimulation therefore represents a tool to investigate the integrative central neurophysiology of penile erection.

\section{Perspectives}

The present results emphasize the importance of the spinal coordination of various autonomic nuclei leading to penile erection. It has been proposed that the intermediate gray matter could represent a coordinating site between sympathetic and parasympathetic nuclei (20). In rats this area is retrogradely labeled over the T12-S2 spinal segments after pseudorabies injection in the corpus cavernosum, suggesting the presence of interneurons potentially involved in the coordination between the parasympathetic lumbosacral and the sympathetic thoracolumbar outflows. Further experiments are now required to explore the anatomic and functional relationship between MPOA and spinal cord structures involved in the control of penile erection.

The authors gratefully acknowledge Dr. K. E. McKenna for helpful suggestions on the manuscript.

All animal experiments have been carried out in accordance with theE uropean Communities Council Directive of 24 N ovember (86/609/ $E E C)$ on the use of laboratory animals. All efforts were made to minimize animal suffering and to reduce the number of animals used.

Address for reprint requests: F. Giuliano, Service d'Urologie, Hôpital de Bicêtre, 78 rue du Général Leclerc, 94270 Le Kremlin Bicêtre Cedex, France.

Received 24 F ebruary 1997; accepted in final form 26 August 1997.

\section{REFERENCES}

1. Andersson, K. E., and G. Wagner. Physiology of penile erection. Physiol. Rev. 75: 191-236, 1995.

2. Andersson, P. O., J . Björnberg, S. R. Bloom, and S. Mellander. Vasoactive intestinal polypeptide in relation to penile erection in the cat evoked by pelvic and by hypogastric nerve stimulation. J . Urol. 138: 419-422, 1987.

3. Argiolas, A., M. R. Melis, and R. Stancampiano. Role of central oxytocinergic pathways in the expression of penile erection. Regul. Pept. 45: 139-142, 1993.

4. Bacq, Z. M. Impotence of the male rodent after sympathetic denervation of the genital organs. Am. J . Physiol. 96: 321-330, 1931.

5. Bacq, Z. M. Recherches sur la physiologie et la pharmacologie du système nerveux autonome. XII. Nature cholinergique et adrénergique des diverses innervations vasomotrices du pénis chez le chien. Arch. Int. Physiol. Biochim. Biophys. 40: 311-321, 1935.

6. Creed, K. E., C.J . Carati, and E.J . Keogh. Autonomic control and vascular changes during penile erection in monkeys. Br. J . Urol. 61: 510-515, 1988.

7. Dail, W. G., and A. P. Evan. Experimental evidence indicating that the penis of the rat is innervated by short adrenergic neurons. Am. J . Anat. 141: 203-218, 1974.

8. Dail, W. G., G. Walton, and M. P. Olmsted. Penile erection in the rat: stimulation of the hypogastric nerve elicits increases in penile pressure after chronic interruption of the sacral parasympathetic outflow. J. Auton. Nerv. Syst. 28: 251-258, 1989.

9. Giuliano, F., J . Bernabé, A. J ardin, and J . P. Rousseau. Antierectile role of the sympathetic nervous system in rats. J. Urol. 150: 519-524, 1993.

10. Giuliano, F., O. Rampin, G. Benoit, and A. J ardin. Neural control of penile erection. Urol. Clin. North Am. 22: 747-766, 1995. 
11. Giuliano, F., O. Rampin, J . Bernabé, and J . P. Rousseau. Neural control of penile erection in the rat. J . Auton. Nerv. Syst. 55: 36- 44, 1995.

12. Giuliano, F., O. Rampin, K. Brown, F. Courtois, G. Benoit, and $\mathbf{A}$. J ardin. Stimulation of the medial preoptic area of the hypothalamus in the rat elicits increases in intracavernous pressure. Neurosci. Lett. 209: 1-4, 1996.

13. J änig, W., and E. M. McLachlan. Organization of lumbar sympathetic outflow to distal colon and pelvic organs. Physiol. Rev. 67: 1332-1404, 1987.

14. J ünemann, K.-P., C. Persson-J ünemann, T. F. Lue, E. A Tanagho, and P. Alken. Neurophysiological aspects of penile erection: the role of the sympathetic nervous system. Br. J . U rol. 64: 84- 92, 1989.

15. Langley, J . N., and H. K. Anderson. The innervation of the pelvic and adjoining viscera. J . Physiol. (Lond.) 19: 71- 130, 1895.

16. Lue, T. F., C. A. Gleason, G. B. Brock, P. R. Carroll, and E. A Tanagho. Intraoperative electrostimulation of the cavernous nerve: technique, results and limitations. J. Urol. 154: 14261428, 1995.

17. Lue, T. F., T. Takamura, M. Umraiya, R. A. Schmidt, and E. A. Tanagho. Hemodynamics of canine corpora cavernosa during erection. Urology 24: 347-352, 1984.

18. Lue, T. F., S. J . Zeineh, R. A. Schmidt, and E. A. Tanagho. Neuroanatomy of penile erection: its relevance to iatrogenic impotence. J. Urol. 131: 273-280, 1984.

19. Marson, L., and K. E. McKenna. Stimulation of the hypothalamus initiates the urethrogenital reflex in male rats. Brain Res. 638: 103-108, 1994.
20. Marson, L., K. B. Platt, and K. E. McKenna. Central nervous system innervation of the penis as revealed by the transneuronal transport of pseudorabies virus. Neuroscience 55: 263-280, 1993.

21. McConnell, J ., G. S. Benson, and J . Wood. Autonomic innervation of the mammalian penis: a histochemical and physiological study. J . Neural Transm. 45: 227-238, 1979.

22. Meisel, R. L., and B. D. Sachs. The physiology of male sexual behavior. In: The Physiology of Reproduction (2nd ed.), edited by E. Knobil and J . Neill. New York: Raven, 1994, p. 3-105.

23. Nadelhaft, I., and A. M. Booth. The location and morphology of preganglionic neurons and the distribution of visceral afferents from the rat pelvic nerve: a horseradish peroxidase study. J . Comp. Neurol. 226: 238-245, 1984.

24. Rampin, O., F. Giuliano, P. Dompeyre, and J . P. Rousseau. Physiological evidence of neural pathways involved in reflexogenic penile erection in the rat. Neurosci. Lett. 180: 138-142, 1994.

25. Semans, J . H., and O. R. Langworthy. Observations on the neurophysiology of sexual function in the male cat. J. Urol. 40: 836-846, 1938

26. Sjöstrand, N. O., and E. K. Klinge. Principal mechanisms controlling penile retraction and protrusion in rabbits. Acta Physiol. Scand. 106: 199-214, 1979.

27. Swanson, L. W. The hypothalamus. In: Handbook of Chemical Neuroanatomy: Integrated Systems of the CNS, edited by $A$. Bôrklund, T. Hôkfelt, and L. Swanson. Amsterdam: Elsevier, 1987, vol. 5, part 1, p. 1-124. 